\author{
PENCA, Jerneja, Transnational legal transplants and legitimacy : the example \\ of 'clean' and 'green' development mechanisms, Legal Studies, 2016, Vol. 36 No.
}

4, pp. 706-724, https://doi.org/10.1111/lest.12132

\begin{abstract}
The introduction of the Green Development Mechanism (GDM) as a governance tool for biodiversity conservation is presented as a legal transplant, originating in the Clean Development Mechanism from the climate regime. The case provides an instance of a transplanted legal idea not from one jurisdiction to another but between two transnational regimes. The legal transplantation approach highlights the motives for replication and factors that hinder it. In this context, the discussion reveals that while the GDM was constructed for effectiveness concerns, it was presented as a transplant in order to import to the newly established model legitimacy from the original one. Yet, a uniform acceptance of the transplant was prevented because of divergent evaluations of the original model. The existence of several, not one, ideologies and perceptions explains why transplanting is a highly unpredictable strategy for fostering acceptance of a legal idea in the transnational space, and ultimately for its implementation. Following the recognition that legitimacy cannot be inherited, the initiative employed a mixed strategy to ensure its acceptance, based on the democratic principles and effectiveness that are expected from non-state authorities, as well as the consensusbased, treaty-grounded 'rules of the game' of state actors. The case highlights how the universal endorsement of all states, and the appearance of alignment with international norms and intergovernmental institutions, remain significant goals of transnational initiatives.
\end{abstract}




\section{Transnational Legal Transplants and Legitimacy: The Example of 'Clean' and 'Green' Development Mechanisms}

\section{INTRODUCTION}

Policy-makers around the world are intensively pursuing workable legal solutions to perennial problems. Conventionally, a source of inspiration for legal reform has been a pragmatic look at what has worked so far in similar settings. In comparative legal scholarship, the study of transfers of legal ideas and institutions across jurisdictions and legal cultures has been captured by the 'legal transplant' approach. ${ }^{1}$ The legal transplant approach however has largely been unexplored in the study of transnational ("beyond the state") $)^{2}$ law. Nevertheless, the ability to discuss the origin and intention of legal ideas is no less important in this domain, in particular for two reasons. From the analytical point of view, recent legal fixes offer to scholars captivating stories of an amorphous governance plane, and of social diversity and agency within it. ${ }^{3}$ From the effectiveness point of view, transferring existing legal models may result in such workable solutions as are hoped by the appeals for originality. ${ }^{4}$

\footnotetext{
${ }^{1}$ See in particular, M. Graziadei, 'Comparative Law as the Study of Transplants and Receptions' in M. Reimann and R. Zimmermann (eds.), Oxford handbook of comparative law (Oxford: Oxford University Press, 2006); J. Fedtke, 'Legal transplants', in: J. M. Smits (ed.), Elgar Encyclopedia of Comparative Law (Cheltenham: Edward Elgar Publishing, 2006); W. Twining, 'Social Science and Diffusion of Law' (2005) 32(2) J. of Law and Sociology 203; F. Schauer, The Politics and Incentives of Legal Transplantation, in J. S. Nye Jr. \& J. D. Donahue (eds.), Governance in a Globalizing World (Washington: Brookings Institution Press, 2000); E. M. Wise, 'The Transplant of Legal Patterns' (1990) 37 American J. of Comparative Law 1. ${ }^{2}$ See, e.g., P. H Glenn, 'A Transnational Concept of Law' in P. Cane and M. Tushnet (eds), The Oxford Handbook of Legal
Studies (Oxford: Oxford University Press, 2003); T. C. Halliday and G. Shaffer, 'Transnational Legal Orders' in T. C. Halliday
and G. Shaffer, Transnational Legal Orders (Cambridge: Cambridge University Press, 2016).

${ }^{3}$ For examples in the environmental field, see, N. Affolder, 'Transnational Conservation Contracts' (2012) 25 Leiden Journal of International Law 443; V. Heyvaert, 'What's in a Name? The Covenant of Mayors as Transnational Environmental Regulation' (2013) 22 Review of European, Comparative and International Environmental Law 78; S. Bernstein et al., 'A tale of two Copenhagens: Carbon markets and climate governance' (2010) 39 Millennium-Journal of International Studies 161.

${ }^{4}$ See the outcome document of the recent Rio+20 summit in 2012, replete with references to 'innovative', 'new' and 'novel'
} 
This article presents one such exciting story of a recent legal fix. It studies, from the perspective of a legal transplant, a specific means for improvement of biodiversity governance - the Green Development Mechanism (GDM) and its subsequent transformations into Green Development Initiative (GDI) and Verified Conservation Areas (GDI-VCA) ${ }^{5}$. The perspective generated by the legal transplantation literature upsets complacency with labelling the GDM as pluralistic "decentered" regulation, ${ }^{6}$ or privatised, ${ }^{7}$ or market ${ }^{8}$ approaches to the global goal of conservation of biodiversity. The proposed perspective pushes the analysis further: it invites us to locate more precisely the origin of the scheme, including the intentions of the transplant, helping us to better understand and evaluate some of the actions taken by the proponents of a legal change. This task carries specific importance because the GDM is essentially a nonstate initiative and, as such, subject to different interrogations about its right to regulate and govern than if it was a governmental actor. ${ }^{9}$

Through demonstrating the usefulness of the transplant approach in making sense of the process of the GDM transplantation, the aim of the article is to extend the scholarship on legal transplants to bear its relevance in the transnational domain.

\footnotetext{
approaches and arrangements; The Future We Want, Resolution of the General Assembly, A/RES/66/288.

${ }^{5}$ The ongoing modifications of the initiative's name render the analysis confusing and unavoidably bewilder the reader. Generally, the acronyms "GDM", "VCA" and "GDI" relate to the same initiative, launched by the same promoters, but point to different stages of its transformation, characterized in particular by how the initiative presents itself.

${ }^{6}$ C. Scott, 'Analysing Regulatory Space: Fragmented Resources and Institutional Design' (2001) Public law 329; J. Black, 'Decentring Regulation: Understanding the Role of Regulation and Self-Regulation in a "Post-Regulatory" World' (2001) 54 Current Legal Problems 103; B. Lange, 'Regulatory Spaces and Interactions: An Introduction' (2003) 12 Social \& Legal Studies 411

${ }^{7}$ C. T. Reid, 'The Privatisation of Biodiversity? Possible New Approaches to Nature Conservation Law in the UK' (2011) 23 J. of Environmental Law 203.

${ }^{8}$ J. Penca, 'Marketing the Market: The Ideology of Market Mechanisms for Biodiversity Conservation' (2013) 2 Transnational Environmental Law 235; C. T. Reid, 'Between Priceless and Worthless: Challenges in Using Market Mechanisms for Conserving Biodiversity’ (2013) 2 Transnational Environmental Law 217.

${ }^{9}$ S. Wheatley, 'Democratic governance beyond the state: the legitimacy of non-state actors as standard setters', in A. Peters, L. Koeclin, T. Förster and G. Zinkernagel Fenner (eds), Non-state actors as standard setters (2009); S. Bernstein and B. Cashore, 'Can non-state global governance be legitimate? An analytical framework' (2007) 1 Regulation \& Governance 347-371; S. Schaller, 'The democratic legitimacy of private governance: An analysis of the ethical trading initiative' (2007) INEF Report 91/2007; J. Steffek, 'The Legitimation of International Governance: A Discourse Approach' (2003) 9(2) European J. of International Relations 249-275.
} 
Contrary to the usual focus of the literature on transfers of legal ideas across national jurisdictions (horizontal transplantation), and between the international and the domestic plane (vertical transplantation),${ }^{10}$ this article zooms in on a move that occurred between two transnational regimes (transnational horizontal transplantation). The consideration of legal transfers in this context identifies factors that are influencing the move in this context. One key message from the study of a horizontal transnational transplantation is that the transplantation of a legal idea is a separate process from the transplantation of that legal idea's legitimacy, ${ }^{11}$ acceptance or recognition, but constitutive to the legal idea itself. Two ideas inform the analysis. First, non-state actors' proposals for legal ideas are not automatically accorded the status of transnational law. Unlike States' initiatives, where consent forms the basis (albeit not the only) to the legitimacy of the rule, ${ }^{12}$ transnational regulatory ideas have yet to "explain and defend" themselves, ${ }^{13}$ or construct their own legitimacy ${ }^{14}$ vis-à-vis relevant communities ${ }^{15}$. Second, legitimacy is key to the viability of a regime and operates separately from the normative development. ${ }^{16}$ The present article links these two ideas in the context of the transplantation process. The GDM is interesting as a case study of how legitimacy of a non-state actor is constructed and understood by various

\footnotetext{
${ }^{10}$ A. Dolidze, 'Bridging Comparative and International Law: Amicus Curiae Participation as a Vertical Legal Transplant' (2015) 26(4) European J. of International Law 851-880.

${ }^{11}$ In discussing 'legitimacy' a well-recognised fundamental distinction operates between the normative and popular/empirical/sociological/descriptive legitimacy, where the former asks whether an institution has a right to rule and the latter is concerned whether people or certain audiences accept that institution as legitimate; D. Bodansky, 'Legitimacy in International Law and International Relations', in J. L. Dunoff and M. A. Pollack, Interdisciplinary Perspectives on International Law and International Relations: The State of the Art (Cambridge: Cambridge University Press 2012), 321-42. When referring to 'legitimacy', this article considers its popular/empirical/sociological/descriptive dimension, unless otherwise stated.

${ }^{12}$ T. Franck, Fairness in International Law and Institutions (1995), pp. 28-29.

${ }^{13}$ Steffek, n above 9, p 258.

${ }^{14}$ Black, $\mathrm{n}$ above 6.

${ }^{15}$ I. Hurd, 'Legitimacy and Authority in International Politics' (1999) 53(2) International Organization 379-408, at 388.

${ }^{16}$ E. Hey, 'Sustainable Development, Normative Development and the Legitimacy of Decision-making' (2003) 34 Netherlands Yearbook of International Law 3, p 13.
} 
audiences and how those legitimacies interplay with the operation of a regulatory regime. In particular, the case reveals the factors, which the non-state actor believes are relevant for building its credibility, and the mechanisms, which it employs to attain it. In this process, the relationship to interstate schemes and compliance with international (inter-state) norms turn out to be of foremost importance.

The article is structured as follows. It first outlines the concept of a legal transplant and the pertinent scholarship, demonstrating how the present piece advances it. In the second step, it considers the background to the emergence of the GDM as a way of introducing the inspiring legal idea and the intention vested into the transplant. It then examines the socio-legal difficulties in the process of implementing the idea before turning to the subsequent outcome and the scheme's actual functioning. Here, the piece focuses on the transnational scheme's ways of asserting itself and of constructing its identity (and legitimacy) away from that of a transplant.

\section{LEGAL TRANSPLANTING}

The concept of legal transplant has become a topos in comparative legal scholarship, a means to studying the historical relationships among the world's legal systems and explaining legal change. Alan Watson put it on a map in 1974 by referring to moves of legal materials from one jurisdiction or person to another. ${ }^{17}$ The focus on the moves has motivated scholarly studies which have highlighted both the extent to which legal ideas are essentially borrowed, rather than invented locally, ${ }^{18}$ and the difficulties involved in transferring law and institutions in a 'cut and paste' manner, suggesting that law is in

\footnotetext{
${ }^{17}$ A. Watson, Legal Transplants: An Approach to Comparative Law (1974).

${ }^{18}$ Ibid.; articulated also in Watson's other works.
} 
fact different each time it changes social context. ${ }^{19}$ Over time, the legal transplant approach has become refined and now accords importance to the social and political context to which transfers occur, largely rejecting the Watson's earliest suggestion that "legal rules move easily and are accepted into the system without too great difficulty [...] even when the rules come from a very different kind of system." ${ }^{20}$ The approach nevertheless remains a timeless platform for engaging with the nature of law as torn between autonomous and socially embedded. Overall, it reinforces the view of law as underpinned by complex, rather than uniform, cultural and societal dimensions. ${ }^{21}$ Analyses within this frame inevitably grapple with the extent to which law preserves a sort of autonomy (expecting that well-intentioned law and institutions can travel freely across space) on the one hand, and the extent to which law is assimilated in society (considering law as a cultural and social object) on the other.

Concrete analyses benefit from this theoretically informed background. Framing the GDM as a legal transplant brings to the fore and makes sense of a series of surprising twists as they are caused by legal ideas being implanted into a new context of another international regime. In contrast to viewing the GDM as a discrete legal idea, the awareness of it as a legal transplant first makes the chain of transformations of the GDM visible. It then increases the alertness to initial motivations of the transplant (i.e. the intentions by the promoters of the GDM when the mechanism was being designed and its effects intended), as well as to the difficulties in its practical implementation (i.e. the factors prompting its transformation to GDI-VCA).

\footnotetext{
${ }^{19}$ O. Kahn-Freund, 'On Use and Misuse of Comparative Law' (1974) 37 Modern Law Rev. 1; P. Legrand, 'The Impossibility of Legal Transplants' (1997) 4 Maastricht J. of European and Comparative Law 111.

${ }^{20}$ Watson, $\mathrm{n}$ above 17 , pp 95-6.

${ }^{21}$ A. Riles, 'Comparative Law and Socio-legal Studies' in M. Reimann and R. Zimmermann (eds.), Oxford handbook of comparative law (2006); R. Cotterell, Comparative Law and Legal Culture, in M. Reimann and R. Zimmermann (eds.), Oxford handbook of comparative law (2006)
} 
While legal borrowings initially were, and predominantly remain, studied in the context of domestic jurisdictions, they have been examined also in the international setting. ${ }^{22}$ Here, "horizontal legal borrowing" across national legal systems has been contrasted with "vertical legal borrowing" taking place between the international and national systems. ${ }^{23}$ In the latter, a further difference has been made between the transfer of international legal ideas to domestic contexts ("downward diffusion") and a contrasting process of the transfer of domestic legal institutions into international law ("internationalization"). ${ }^{24}$ The imagery of the realm, where legal transplantations occur, is one of various national jurisdictions but a uniform international level.

This piece advances this mapping exercise. It suggests to consider the "above-state" level not as homogenous, but as itself comprised of various regimes. In the case of the GDM, the concept of a legal transplant is invoked in the context of moving law from one substantive international regime (in this case, a climate change agreement) to the other (the biodiversity conservation regime). My analysis draws attention to the fact that legal borrowings can and do occur between two international regimes, each of which is determined by a distinct set of circumstances and, in accordance with the understanding of a regime, ${ }^{25}$ functions in more or less autonomous ways. Transplantation within the transnational plane thus deserves just as much attention as any of the so far considered processes. It is important to point out that legal diffusion at the "above-state" level involves also actors other than states, and it is thus more

\footnotetext{
22 While the present article builds on the significant distinction between "transnational" and "international" law, it should insofar as "transnational" expands the scope of "international" law - be conceived also within the context of the research on "comparative international law", which explores possibilities of using comparative methods and approaches in studying international law; see the special issue of the American Journal of International Law 109(3) (2015).

${ }^{23}$ J. B. Wiener, 'Something Borrowed for Something Blue: Legal Transplants and the Evolution of Global Environmental Law' (2001) 27 Ecology Law Quarterly 1295.

${ }^{24}$ Dolidze, $\mathrm{n}$ above 10, pp. 852-3.

${ }^{25}$ S. D. Krasner, 'Structural Causes and Regime Consequences: Regimes as Intervening Variables' (1982) International Organization 185, p 186.
} 
adequately termed transnational than international. The specific transplantation route that this article detects - borrowing across transnational regimes - is shown in Figure 1.

The increased complexity in the proposed map is descriptively more accurate. It is also conducive to better theorizing of the dynamics of the transplant process. The case of the GDM demonstrates that the economic, social, political and cultural factors, which influence the horizontal transplant across domestic jurisdictions, ${ }^{26}$ remain valid in the process of horizontal transnational transplantation. But the case primarily brings attention to the decisive role played by subjective evaluations, worldviews and ideological considerations. It explains how these can be both shared and divisive in transnational regimes, and how they shape common definitions of what is legitimate, ${ }^{27}$ this being a significant factor in legitimising or rejecting a legal idea by a transnational actor.

\section{THE ORIGIN OF THE TRANSPLANT: FROM 'CLEAN' TO 'GREEN' DEVELOPMENT MECHANISM}

Let us begin the discussion of the initiative Green Development Mechanism (GDM) by concentrating for a moment on its original name. This evokes a direct association to Clean Development Mechanism (CDM) of the climate change regime. The CDM was launched by the 1997 Kyoto Protocol to the UN Framework of the Convention on Climate Change forming part of specific policy instruments for combating climate

\footnotetext{
${ }^{26}$ Kahn-Freund, n above 19.

${ }^{27}$ Hurd, n above 15, p 388; Black, n above. 6, pp. 146.
} 
change and achieving sustainable development at the same time. ${ }^{28}$ As one of the three so-called flexibility mechanisms designed by the Protocol, the CDM was justified in a sort of a deal between the developed and developing countries: it was envisaged to facilitate the obligation of meeting quantified reduction commitments by the developed countries while the major buy-in for the developing countries was its promise for capacity building and technology transfer. The CDM was seen as a revolution in international environmental governance for representing "the first global environmental market mechanism" 29 and a model for partnering with the private sector in the implementation of an international legal regime. ${ }^{30}$ But it is important to emphasise that the CDM remained entirely embedded in an international treaty regime. It is supervised by a body that is under the authority and guidance, and ultimately answerable to the State Parties of the Kyoto Protocol. ${ }^{31}$

It is entirely clear that the CDM represented the ideational basis for the development of the new mechanism and lent the 'working title' to the GDM. ${ }^{32}$ The GDM was envisaged to reproduce the virtues of the CDM. To begin with, it was expected to import the benefit of drawing on the financial and technical resources of the private sector into the biodiversity regime. This is based mostly around the Convention on Biological

\footnotetext{
${ }^{28}$ Art 12 of the Kyoto Protocol to the United Nations Framework Convention on Climate Change (Kyoto Protocol), Kyoto (Japan), 11 December 1997, entered into force 16 February 2005. The CDM allows developed (Annex I) countries to implement projects aimed at emission reduction in developing (non-Annex I) parties and in that way gain 'certified emissions reductions' or 'credits' that count towards their reduction commitments.

${ }^{29}$ C. Streck, 'The governance of the Clean Development Mechanism: the case for strength and stability' (2007) 259 Environmental Liability 91, p 100.

${ }^{30}$ Bringing the private sector on board has made the CDM 'arguably the most innovative experiment of international law to date'; ibid., at 99; see also C. Streck, 'New partnerships in global environmental policy: the Clean Development Mechanism' (2004) 13 The J. of Environment \& Development 295.

${ }^{31}$ Art 12(4) of the Kyoto Protocol

${ }^{32}$ GDM, The GDM 2010 Initiative Report, Toward a market-based financial mechanism to support biodiversity and development, An information document for the 10th Conference of the Parties of the Convention on Biological Diversity, Nagoya, Japan, 18-29 October 2010, <http://gdm.earthmind.net/files/gdm-cop10-inf-doc.pdf>, p 3.
} 
Diversity (CBD), ${ }^{33}$ whose financing model has been seen as problematic since the early years of the Convention. ${ }^{34}$ The proponents of the GDM highlighted the limits of the biodiversity regime in comparison to the climate one:

"Since its inception in 2002, the CDM has generated US\$23 billion in carbon offset payments, and catalyzed well over US $\$ 100$ billion in private sector investment in low carbon projects. In contrast, the CBD has done very little until now to attract the private sector, and has instead relied on bi-lateral and multi-lateral aid contributions." 35

Proposals have repeatedly been made to complement the legal regime's reliance on public funds with stronger built-in incentives in order to fill the biodiversity financing gap. ${ }^{36}$ But while the CBD text and process had failed to establish incentives, the GDM responded to those calls and proposed to:

"mobilise private finance by linking biodiversity supply with biodiversity demand through a market mechanism. For instance, by establishing a standard and an accrediting process for certifying the management of geographically-defined areas in accordance with the $\mathrm{CBD}$, and by facilitating a functional market for those areas,

\footnotetext{
${ }^{33}$ Convention on Biological Diversity (CBD), Rio de Janeiro, 5 June 1992, entered in force 29 December 1993

${ }^{34}$ The resources provided in the predicted manner are insufficient, project-tied, and do not remunerate the full benefits that biodiversity generates; S. Menzel, "Financial support for biodiversity protection in developing countries-does the CBD mechanism lead to an appropriate level of biodiversity protection?," in M. Markusen et al., Valuation and Conservation of Biodiversity Interdisciplinary Perspectives on the Convention on Biological Diversity (2005). Additionally, there have been concerns over a disproportionate influence by the donors - developed states - over the allocation of funds; H. Sjöberg, 'Restructuring the Global Environment Facility' (1999), <http://207.190.239.143/outreach/outreach-publications/WP13-Restructuring_the_GEF.pdf>, P. Roberts, 'International Funding for the Conservation of Biological Diversity: Convention on Biological Diversity' (1992) 10 Boston International Law J. 303, pp. 325, 343.

35 A. James and F. Vorhies, 'A Green Development Mechanism for Biodiveristy?' The Ecosystems Marketplace, <http://www.ecosystemmarketplace.com/pages/dynamic/article.page.php?page_id=7786>

${ }^{36}$ J. A. McNeely, Economics and Biological Diversity: Developing and Using Economic Incentives to Conserve Biological Resources (1988), p. xiii; D. M. Bodansky, 'International Law and the Protection of Biological Diversity' (1995) 28 Vanderbilt J. of Transnational Law 623; C. Perrings and M. Gadgil, 'Conserving Biodiversity: Reconciling Local and Global Public Benefits,' in I. Kaul (ed) Providing global public goods: managing globalization (Oxford: Oxford University Press, 2003); K. Mullan, A. Kontoleon and T. Swanson, 'Towards an International Market-based Instrument to Finance Biodiversity Conservation: A Green Development Mechanism’ Technical Background Paper (2009).
} 
financing of GDM-certified areas by willing businesses, investors, consumers and other interested parties such as private foundations and NGOs." ${ }^{37}$

Apart from galvanizing finance, a further benefit of the GDM was identified in approximating the treaty regime (the CBD) to the actual 'end-users' or those stakeholders that take concrete steps in its implementation. Again, based on the CDM's model, the rationale of the GDM was that through tangible, financial incentives, land managers in developing countries could be influenced by the rules and objectives of the CBD. ${ }^{38}$

Overall, the GDM's appeal was foremost practical. As such, the identity of the mechanism could easily be constructed on its own terms. But rather than justifying the introduction of the GDM as enhancing the biodiversity regime, the GDM was promoted also by continuous reference to an already existing (and presumably successfully tested) legal solution - the CDM. The association with the CDM was hoped to grant the emerging instrument the much-needed publicity, a sense of an impending success and acceptability among the states and conservation groups: if the CDM was accepted among the stakeholders, why should the GDM, nothing more than its counterpart in another regime, not be?

This strategy was chosen with the purpose of implanting the legitimacy of the CDM into the GDM; it was hoped that the acceptability of the CDM would be imported into the GDM alongside the legal idea itself. But this the strategy had the effect of reframing the debate about the utility and advantages of the GDM (such as, the value of establishment of precise standards for conduct or the extent and ways of involving

\footnotetext{
${ }^{37}$ GDM, above n 31 .

${ }^{38}$ James and Vorhies, above n. 35, pp. 6-7.
} 
private actors in the implementation of an intergovernmental treaty) into an evaluation of the CDM.

But the extent to which the CDM can be seen as providing positive experience was and remains a contestable issue. Following the predominantly optimistic take-off, indicated above, highly divergent perspectives have emerged on whether the CDM (and carbon markets more generally) represent a successful legal tool, depending largely on the values and objectives that underlie the assessments. ${ }^{39}$ Thus, while the CDM may be acclaimed for endorsing cost-effectiveness and flexibility and for engaging in the Protocol a crucial stakeholder in the resolution of the problem, ${ }^{40}$ it can also be criticised for embodying ecological and social risks and deepening the North-South inequalities. ${ }^{41}$ Overall however, the real-world operation of the mechanism has strayed considerably from the ways in which it was envisaged, ${ }^{42}$ raising the possibility that the implementation of objectives is not as predicted. The CDM's reputation was also critically affected by the charges that carbon markets are vulnerable to corruption and fraud. ${ }^{43}$ Finally, the fundamental ability of the CDM to meet the multiple objectives of greenhouse gas reduction and sustainable development has been questioned. ${ }^{44}$

Against the background of a very mixed legacy of the CDM and mixed perceptions of it, the decision by the promoters to frame a nascent biodiversity financing and

\footnotetext{
${ }^{39} \mathrm{~K}$. Bäckstrand and E. Lövbrand, 'Planting trees to mitigate climate change: Contested discourses of ecological modernization, green governmentality and civic environmentalism' (2006) 6 Global Environmental Politics 50.

${ }^{40}$ M. Wara, 'Measuring the Clean Development Mechanism's Performance and Potential', Working paper 6, Program on Energy and Sustainable Development (2006).

${ }^{41}$ Bäckstrand and E. Lövbrand, $\mathrm{n}$ above 39.

${ }^{42}$ E. Cloatre and N. Wright, 'A Socio-legal Analysis of an Actor-world: The Case of Carbon Trading and the Clean Development Mechanism' (2012) 39 J. of Law and Society 76.

${ }^{43}$ L. Lohmann, 'Regulation as corruption in the carbon offset markets' in S. Böhm and S. Dabhi (eds), Upsetting the offset: the political economy of carbon markets (2009); International Criminal Police Organisation (INTERPOL), Guide to Carbon Trading Crime (2013).

${ }^{44}$ C. Sutter and J. C. Parreño, 'Does the current Clean Development Mechanism (CDM) deliver its sustainable development claim? An analysis of officially registered CDM projects' (2007) 84 Climatic Change 75.
} 
implementation mechanism as a replication thereof was a risky strategy. On the one hand, it was likely that the positive assessments of the CDM would be capable of lending sympathies to the GDM. But it was just as likely that the existing negative opinions of the CDM would produce disbelieve towards the GDM.

The reliance on analogy was certainly avoidable, as the institutional, legal and social contexts of the emergence of these two mechanisms were substantively different. The fundamental difference between the starting points of the CDM and the (envisaged) GDM was the fact that while the CDM was embedded in a treaty regime with mandatory quantifiable goals, the GDM could not contribute to any binding target, as these are absent from the CBD. This legal fact considerably diminished the GDM's potential scope. ${ }^{45}$ The only plausible scenario for the GDM was to operate as a voluntary regulatory option and work towards fulfilling voluntary commitments of the parties to the CBD. ${ }^{46}$ As such, its participants would be driven mostly by "beyondcompliance" motives, but the GDM would also be capable of fulfilling governmental requirements and act as an investment opportunity. ${ }^{47}$ Thus, the original intention to establish, "[1]ike the CDM...a standard-setting and certification process to enable a market-based approach for generating new financial resources" ${ }^{48}$ could never be fulfilled entirely, because the GDM was, due to the legal structure of the regime, unable to become fully "like the CDM". The theoretical hurdles to the transplant were followed by the practical ones.

\footnotetext{
${ }^{45}$ The GDM initially contemplated the idea of becoming a means of implementation of a compulsory requirement of the CBD in the future, but this ambition was too far-fetched. GDM, n above 20, p 11 .

${ }^{46}$ Earthmind, The BioAreas Standard \& Registry for Biodiversity-Responsible Area Management, Pilot Phase Version 1.0, (1 March 2012), <http://gdi.earthmind.net/files/BioAreas-Reference-Guide-Version1-01Mar2012.pdf>, at. 3

${ }^{47}$ Earthmind, The Business Case for BioAreas (01 March 2012), <http://gdi.earthmind.net/files/BioAreas-Business-Case01Mar2012.pdf>

${ }^{48}$ GDM, op. cit. 32, pp. 3, 8 .
} 


\section{THE CHALLENGE OF TURNING INTENTIONS INTO ACTION}

The GDM started its life as a non-state initiative, but at the immediate periphery of the state-led negotiations. The first discussions about a GDM can be traced to a side event during the $9^{\text {th }}$ CBD Conference of Parties (COP) in 2008, which looked at an international payments scheme for green development. ${ }^{49}$ The next year, the first Expert Workshop on GDM was held with a view to exploring the opportunities for establishing a GDM and its possible design. ${ }^{50}$ While one of the stated objectives of the workshop was "to establish whether there is a valid case for a GDM", ${ }^{51}$ the discussion as reported showed no reluctance and only reiterated the need for such a mechanism, focussing solely on its appropriate design. Subsequently, a series of expert workshops, consultations, seminars, and other meetings about the idea of a GDM took place at an increasingly frequent rate and in fora far beyond those of the CBD, encompassing consultations with intergovernmental agencies, business, individual countries and NGOs. ${ }^{52}$ The purpose of these activities was to raise sufficient interest in the scheme and gather support for its (operative) launch at the $10^{\text {th }}$ CBD COP in Nagoya in 2010, an anniversary event infused with large expectations over a number of issue-areas.

At Nagoya, the information document on the GDM Initiative was presented to the States Parties as an official Information note by the Executive Secretary ${ }^{53}$ and discussed under the topic of resource mobilization. There it suddenly became most clear that the idea of a GDM, forming part of a broader "innovative financial mechanisms" was too

\footnotetext{
${ }^{49}$ GDM, n above $32, \mathrm{p} 47$.

50 GDM, Report from an Expert Workshop: Towards a Green Development Mechanism, 〈http://gdm.earthmind.net/files/ReportfromFeb09ExpertWorkshopwithAnnex1.pdf〉.

${ }^{51}$ Ibid.

${ }^{52}$ GDM, $\mathrm{n}$ above 32, pp 44-47.

${ }^{53} \mathrm{UNEP} / \mathrm{CBD} / \mathrm{COP} / 10 / \mathrm{INF} / 28$ (GDM 2010 Initiative report).
} 
controversial for a broad consensus of the Parties. Many Parties to the Convention agreed that insufficient resources continue to impede successful implementation of the treaty and held favourable views about innovative financial mechanisms, underlining that the purpose was to supplement, rather than replace the existing financial mechanism of the Convention. ${ }^{54}$ But some Parties were sceptical about funds that do not come from public sources and opposed to making reference to GDM or other concrete initiatives in the decision of the COP. ${ }^{55}$ The final decision on resource mobilization thus made no reference to the GDM in the text. ${ }^{56}$

The twist - when some, even if few, State Parties turned down an initiative that counted with the endorsement by all - is significant for two reasons. First, it reflects a belief in the COP's legitimacy capital. While the legislative function of the COPs has been acknowledged, ${ }^{57}$ the important legitimating function that these treaty bodies can perform, in particular (in relation) to transnational initiatives, has so far been overlooked.

Second, the twist is revealing of the complexity of the transplant process. This is driven by the collective aspiration for effectiveness, but the ideas about how or what law can bring it about remain contestable. The twist provides evidence for the fact that regulatory techniques are far from being a result of a purely rational process, and

\footnotetext{
${ }^{54}$ Earth Negotiations Bulletin, CBD COP 10 Highlights, 9(534), 20.10.2010; <http://www.iisd.ca/vol09/enb09536e.html> (concretely, Bolivia made a statement about the source of financial resources, the African Group and Malaysia opposed reference to the Green Development Mechanism, and Japan opposed all references to specific initiatives)

55 Ibidem.

${ }^{56} \mathrm{UNEP} / \mathrm{CBD} / \mathrm{COP} / 10 / 3$ (Strategy for resource mobilization in support of the achievement of the Convention's three objectives); in the aftermath of the CBD COP, the efforts to clarify issues surrounding the mobilization of financial resources to support the achievement of the 2020 Aichi Biodiversity Targets, including the role of "innovative financing mechanisms", moved to more informal avenues; see F. Farooqui, and M. Schultz, Co-chairs' Summary of Dialogue Seminar on Scaling up Biodiversity Finance, Quito 6-9 March 2012, <www.cbd.int/doc/meetings/fin/ds-fb-01/official/ds-fb-01-02-en.pdf>

57 J. Brunnée, 'COPing with Consent: Law-Making Under Multilateral Environmental Agreements' (2004) 15 Leiden J. of International Law 1; R. R. Churchill and G. Ulfstein, 'Autonomous Institutional Arrangements in Multilateral Environmental Agreements: A Little-Noticed Phenomenon in International Law' (2000) 94 American J. of International Law 623. COP decisions are considered capable of becoming a plausible source of treaty interpretation and count as sources of treaty interpretation; Article 31(3) or the Vienna Convention on the Law of the Treaties; M. Scheinin, 'Impact on the Law of Treaties' in M. T. Kamminga and M. Scheinin, The Impact of Human Rights Law on General international Law (Oxford: Oxford University Press, 2009 ), p 33.
} 
reaffirms the continual utility of a sociological perspective in approaching legal ideas. ${ }^{58}$ It is perceptions and ideas, rather than crude facts, which explain both the support and rejection of the GDM.

In so far as the GDM presented itself as a replication of another legal idea (the CDM), it was the association with the latter, which underpinned the receipt of the GDM. In other words, the views of the CDM translated into views about the emerging GDM, regardless of actual similarities in the functioning of the two and the justification of a GDM. However, the proponents of the new biodiversity financing mechanism did not recognise this from the start. They chose the name of "Green Development Mechanism" in order to highlight the intended replication of a model, assuming that it is broadly seen as a success. Paradoxically, the choice of the name is likely to have played a major role in an outcome that worked against them. In retrospect, they noted that "GDM sounded a bit too much like CDM", ${ }^{59}$ which had the effect of alienating both those sympathetic to the CDM and those hostile to it. Those who liked the CDM found the value-added of the nascent mechanism insufficiently separated out and feared that it could replace, rather than supplement existing financial sources in the CBD. ${ }^{60}$ On the other hand, those who disliked the CDM fought against its replication (and implicit recognition of its merit) in another regime. It is significant that the CDM had not been a failure altogether, but evaluations of what counts as "a success" in a legal model as well as expectations about its performance can be very different among stakeholders without this being recognised. Polarised visions of the CDM's merit

\footnotetext{
${ }^{58}$ See, e.g., R. Cotterrell, Law, Culture and Society: Legal Ideas in the Mirror of Social Theory (Ashgate 2006)

${ }^{59}$ GDI, Mobilising Private Sector Finance for Biodiversity Conservation and Sustainable Use, OECD WPBWE Expert Workshop, 09 March 2011, Paris, France, <http://gdi.earthmind.net/files/Vorhies_Presentation-Session-3.pdf>

${ }^{60}$ Particularly, the term "mechanism" in the GDM was disputed, for being "too closely linked" to financial mechanism and official development assistance, which are already enshrined in the CBD; Earth Negotiations Bulletin, n above 52.
} 
prevented any sort of agreement on how to proceed with the GDM and blocked an endorsement of the GDM at the COP. The discussion of the GDM would likely have been different if it had not been packaged as a transplant but as a whole new construct, designed specifically for the biodiversity regime.

The rejection of the GDM must be explained also in terms of the ongoing ideological discourse on the human relationship to nature. Discussions about ethical and political questions concerning the use of markets in designing legal solutions and the application of utilitarian calculations to nature and parts thereof, have in the biodiversity context distinctly developed into institutionalised, collective opposition to the "commodification of nature" 61 and "neoliberalization of nature" 62 . The strong aversion on the part of some states and civil society groups to the reforms in those directions translated into an opposition to the GDM, which represented itself explicitly as marketbased. ${ }^{63}$ The question of the extent to which the GDM actually puts into effect the economic construct of "the market" or converts natural functions into commodities was secondary to the perception that the GDM embodies these processes.

\section{THE ACTUAL TRANSPLANT: A MECHANISM SUI GENERIS}

This section is concerned with the result of the transplantation process. The failure to formally integrate the GDM into the intergovernmental forum led the proponents to

\footnotetext{
${ }^{61}$ See, e.g., A. Lorch, 'Resource mobilisation for the CBD: Innovative financial backtracking?' (2012) Third World Resurgence No. 242/243, <http://www.ifrik.org/resource-mobilisation-cbd-innovative-financial-backtracking>; E. Gómez-Baggethun and M. Ruiz-Pérez, 'Economic Valuation and the Commodification of Ecosystem Services' (2011) 35 Progress in Physical Geography 613.

${ }^{62}$ See, e.g., the special issues of journals (2005) 16(1) Capitalism Nature Socialism 1-137; (2004) 35(3) Geoforum 269-394; (2010) 42(3) Antipode 469-799; (2012) 43(3) Geoforum 363-426; see the seminal piece by K. McAfee, 'Selling nature to save it? Biodiversity and green developmentalism' (1999) 17 Environment and Planning D: Society and Space 133; and a more recent synthesis of the literature and arguments by B. Büscher et. al. 'Towards a synthesized critique of neoliberal biodiversity conservation' (2012) 23 Capitalism Nature Socialism 4

${ }^{63}$ GDM, n above 32, pp 3, 8 .
} 
adopt a new approach to the promotion of the biodiversity initiative. Although the underlying idea of the scheme remains essentially the same and is coordinated by the same institution, the Green Development Initiative (GDI), direct associations to the CDM are now being explicitly avoided.

The construction of an independent image, away from the CDM, can be interpreted as its new legitimating strategy. This is geared towards a greater acceptability among various stakeholders, especially those groups that had expressed their reservations for a mechanism that replicates the CDM. The mechanism is now establishing itself on its own terms and seeking to be judged according to those features, which are its own. The first step was a change in the name. In the aftermath of the Nagoya COP, the initiative re-established itself under the label of "Green Development Initiative BioPositive Approach". ${ }^{64}$ Most recently still, the activities have begun being run on the platform of "Verified conservation areas". ${ }^{65}$ Apart from the name, a crucial aspect of the rebranding was switching away from the notion of "market-based mechanism" and associated terminology. ${ }^{66}$ In continuation, the resulting model will be referred to as VCA-GDI.

In what follows, the upshot of the transplantation is considered from the point of view of its institutional structure and its operation. The resulting mechanism is grossly different from the CDM in both these aspects. Unlike the CDM, which is a mechanism within a treaty regime, "subject to the authority and guidance" to the States Parties to the climate treaty, ${ }^{67}$ the VCA-GDI's relationship to the CBD treaty is less clear-cut and

\footnotetext{
64 A visitor of the "GDM 2010 Initiative" website was redirected to a "GDI" website; GDM 2010 Initiative, <http://gdm.earthmind.net/>; GDI Conserving our planet, hectare by hectare, <http://gdi.earthmind.net/>

${ }^{65}$ Verified Conservation Areas, <http://v-c-a.org/>; GDI, <http://gdi.earthmind.net/>

66 J. Metcalfe and F. Vorhies, 'Exploring the case for a green development mechanism' (2010), $<$ http://www.cbd.int/financial/doc/gdm-exploring-the-case-en.pdf $>$. Today, the scheme is described as a "platform [that] enables conservation to be visible, accountable and marketable"; Verified Conservation Areas, <http://v-c-a.org/>

${ }^{67}$ Art 12(4) of the Kyoto Protocol
} 
so is its institutional status. The institutional hybridity and mixed tactics in gaining legitimacy grant the emerging mechanism a sui-generis nature that breaks with the distinction between governmental and non-governmental.

\section{Institutional hybrid}

At first sight, the VCA-GDI can be located within non-governmental arrangements because it has been coordinated by a Swiss-based NGO, Earthmind, since its inception. But Earthmind holds a number of institutional links to the governmental, intergovernmental and corporate sector. Its office is hosted by the International Union for Conservation of Nature (IUCN). ${ }^{68}$ It also has a business arm, an enterprise registered in France. Core funding for the operation of the VCA-GDI came from the governments of the Netherlands and Switzerland. Representatives of some governments and international bodies are included among the members of an Earthmind's decision-making committees. The VCA-GDI's Steering Committee has despite variations in individual phases - remained devoted to the idea that different stakeholder groups (NGOs, the private sector and governments) of different nationalities sit on it. The operation of the GDI is further provided by an Advisory Committee, which includes around 100 experts. These are individuals from governmental agencies or ministries, intergovernmental bodies, NGOs, universities, businesses and independent consultancies. ${ }^{69}$

As it emerges, the VCA-GDI defies simple cataloguing as either a governmental or nongovernmental actor. Legally, the VCA-GDI operates under an NGO flag. But in

\footnotetext{
${ }^{68}$ As it is known, the IUCN represents a unique hybrid organization, whose members are governments, non-governmental organisations and individual experts.

${ }^{69}$ GDI, GDI Advisory Group, <http://gdi.earthmind.net/files/GDI-Advisory-Group.pdf>
} 
reality, more than a traditional NGO with weak or no links to state authority, the VCAGDI has a number of significant relations to the governmental and corporate views and interests. Also, rather than grounded in a fixed membership base, its organization resembles a network of expert individuals. The VCA-GDI defeats the conceptions of "private" 70 or "non-state, market driven governance", ${ }^{71}$ which are typically contrasted with the state authority. If anything, it would more appropriately be labelled a "transnational network", ${ }^{72}$ a "regulatory network" 73 in order to highlight that the initiative relies primarily on expertise and political (also governmental) influence, rather than the composition of its governing bodies fitting either within or outside the state sector.

\section{Functioning of the VCA-GDI}

The hybrid nature of the VCA-GDI as torn between non-state and state structures extends beyond its structure. Also in terms of its functions, the VCA-GDI could be described as both a non-state certification scheme and a product of the international (i.e. inter-state) treaty. These are examined in turn.

\footnotetext{
${ }^{70}$ J. Clapp, The privatization of global environmental governance: ISO 14000 and the developing world (1998) 4 Global Governance 295; C. Cutler, V. Haufler and T. Porter (eds.) Private Authority and International Affairs (Albany: State University of New York Press, 1999); R. B. Hall and T. J Biersteker (eds.), The Emergence of Private Authority in Global Governance (Cambridge: Cambridge University Press, 2002); H. Schepel, The Constitution of Private Governance: Product Standards in the Regulation of Integrating Markets (2005)

${ }^{71}$ B. Cashore, 'Legitimacy and the Privatization of Environmental Governance: How Non-State Market-Driven (NSMD) Governance Systems Gain Rule-Making Authority' (2002) 15 Governance 503; S. Bernstein and B. Cashore, 'Can Non-State Global Governance be Legitimate? An Analytical Framework' (2007) 1 Regulation and Governance 347

${ }^{72}$ T. Risse-Kappen (ed.) Bringing Transnational Relations Back In: Non-State Actors, Domestic Structures and International Institutions (Cambridge: Cambridge University Press, 1995); R. Lipschutz, Global Civil Society and Global Environmental Governance: The Politics of Nature from Place to Planet (Albany: State University of New York Press, 1996); P. Wapner, Environmental Activism and World Civic Politics (Albany: State University of New York Press, 1996); M. Keck and K. Sikkink, Activists Beyond Borders: Advocacy Networks in International Politics (Ithaca: Cornell University Press, 1998); M. E. Keck and K. Sikkink 'Transnational advocacy networks in international and regional politics' (1999) 51 International Social Science J. 159; T. Risse, S.C. Ropp, and K. Sikkink (eds.) The Power of Human Rights: International Norms and Domestic Change (Cambridge: Cambridge University Press, 1999); P. Newell, Climate for Change: Non-State Actors and the Global Politics of the Greenhouse (Cambridge: Cambridge University Press, 2000).

${ }^{73}$ P. Schmidt, 'Law in the Age of Governance: Regulation, Networks and Lawyers', in J. Jordana and D. Levi-Faur (eds) Regulation in the Age of Governance (Cheltenham: Edward Elgar, 2004)
} 
The VCA-GDI claims to run a "public registry, international standard and best-practice toolkit" ${ }^{74}$ As such, it reflects the functioning of a certification scheme. ${ }^{75}$ While tapping into previously unexplored issue-area of land management under the CBD, the stated purpose and the processes that the VCA-GDI envisages to implement correspond to some known certification programmes, most notably in forestry, fisheries and organic farming. Eco-certification generally has emerged in response to the failure of (national and international) law to control damaging effects of production processes to offer a way to differentiate between conventional and environmentally preferable products. ${ }^{76}$ It is typically run by non-state actors, who, in the absence of the ability to impose compulsory rules, engage market forces to promote particular environmental objectives. The goal is to deliver an assurance of continuously fulfilling a certain quality standard. ${ }^{77}$ Concretely, certification provides consumers with information about the product or service and allows them to demonstrate a preference for more sustainable products, thereby giving the producers an incentive to continue implementing the standards. ${ }^{78}$

\footnotetext{
${ }^{74}$ GDI, <http://gdi.earthmind.net/>

${ }^{75}$ In literature, "certification" is often used interchangeably with "eco-labelling", but the label is only the final step in a process: "The label is a symbol indicating compliance with certain standards, and often is the last, or "customer-facing" element of a certification system. The certification system, by contrast, spans the market from producer to end consumer, involves continual interactions among these various stakeholders in the value chain, and entails numerous processes that are not easily communicated by a consumer label." National Research Council, Certifiably Sustainable: The role of Third-Party Certification Systems: Report of a Workshop (2010), p 5.

${ }^{76}$ L. H. Gulbrandsen, 'Mark of sustainability? Challenges for fishery and forestry eco-labeling' (2005) 47 Environment: Science and Policy for Sustainable Development 8; on forest certification, see also D. Humphreys, Logjam: Deforestation and the crisis of global governance (Earthscan 2006), Chapter 6; E. Meidinger, 'Forest certification as a global civil society regulatory institution,' (2003) Social and political dimensions of forest certification 265; on Marine Stewardship Council as the certification scheme for wild-capture fisheries, see J. Peacey, The Marine Stewardship Council fisheries certification program: Progress and challenges (IIFET 2001); A. Cummins, 'The Marine Stewardship Council: A multi-stakeholder approach to sustainable fishing' (2004) 11 Corporate Social Responsibility and Environmental Management 85.

${ }^{77}$ See e.g. E. E. Meidinger, C. Elliot and G. Oesten, 'The Fundamentals of Forest Certification' in E. E. Meidinger, C. Elliot and G. Oesten (eds), Social and political dimensions of forest certification (2003)

${ }^{78}$ Gulbrandsen, n above 76, p 17.
} 
Current activities of the VCA-GDI involve consolidating an international standard and setting up the necessary methodological and institutional machinery for linking stakeholders, as well as an operational engagement with the projects. The subjects of certification are areas of land; both that land which is ecologically valuable but threatened (thus envisaged for conservation), and land which is undergoing development. An area undergoing certification is required to put in place a management system, designed in accordance with the VCA-GDI-mandated standard. ${ }^{79}$ Significantly, in establishing the acceptable threshold for use or conservation of areas, the VCA-GDI does not establish a substantive new standard or indicators. Instead, it uses existing tools and best practices, as they have been drafted by a wide variety of stakeholders (governmental, inter-governmental, non-governmental and corporate actors). ${ }^{80}$ The VCA-GDI's contribution has been to collect in a single place the existing but scattered standards for their adoption in individual management plans, and to add certain reporting and auditing requirements. The VCA-GDI keeps track of the areas at different stages from their nomination onwards in an online registry. It also makes accessible annual performance reports for each. It acts as coordinating institution.

The initiative today is fully operational. Relevant materials are consistently expanded and reviewed, with the latest certification standard dating from early $2016 .{ }^{81}$ Nineteen conservation areas are currently registered or being considered for certification. ${ }^{82}$ While the areas vary in size, dependence on government funding, and their ecological, economic and social circumstances, a uniform impression emerges about the

\footnotetext{
${ }^{79}$ VCA, Tools for Management Plan, <http://toolkit.earthmind.net/plan/>

${ }^{80}$ The following institutions have for instance drafted standards on which the GDI draws: Global Reporting Initiative, the government of Australia, IUCN, the Nature Conservancy, an EU Parliament committee, Marks \& Spencer and Unilever; VCA, Tools for Conserving Nature, <http://toolkit.earthmind.net/conserve/>; VCA, Tools for Using Natural Resources Sustainably, $<$ http://toolkit.earthmind.net/use/>

${ }^{81}$ VCA, The verified conservation area standard, 〈http://v-c-a.org/files/VCA-Standard-Feb2016.pdf>

${ }^{82}$ VCA, Proposed VCAs, <http://v-c-a.org/proposals/>
} 
motivation of managers for participating in the scheme: their expectation is that the scheme has a promising role to play in linking conservation areas to donors. Stakeholders will participate in the VCA-GDI as long as they perceive the scheme capable of ensuring funding, as this is a crucial condition for effective conservation of exceptional biodiversity.

\section{"Product" of the treaty}

At the same time, the VCA-GDI certification scheme has no intention to operate away from the treaty, the CBD, and its processes. To the contrary, it seeks to establish close normative and institutional links with the inter-state avenue. This can again be interpreted as forming an important part of the current VCA-GDI's strategy to gain wide acceptance by stakeholders. The VCA-GDI now builds its legitimacy by demonstrating that it is allied with the treaty process and in full compliance with international obligations. It does so in essentially three ways.

First, the VCA-GDI presents itself as an independent institution that reviews performance against the $\mathrm{CBD}$ treaty requirements and authoritatively asserts compliance with the treaty. As such, the GDI is directly responding to the corporations' and other users' demand for standards, by which they can claim to implement an environmental treaty, ${ }^{83}$ in this case, the CBD in the segment of land use. The VCAGDI has addressed the request for biodiversity-conscious management of land by collecting standards for the use of the private sector and introducing them as valid standards for compliance with the CBD requirements. As a matter of fact, the VCAGDI did not create new standards - standards for sustainable land use already exist.

\footnotetext{
${ }^{83}$ N. Affolder, 'The Market for Treaties' (2010) 11 Chicago J. of International Law 159.
} 
They originate in national laws, ${ }^{84}$ certain international treaties, ${ }^{85}$ lending banks' guidelines,${ }^{86}$ companies $^{87}$ or NGOs instruments, ${ }^{88}$ to name a few sources. The VCAGDI refers to them in establishing a combined, single standard and claims that they comply with the provisions of the CBD, regardless of whether or not the specific standard itself actually complies with the CBD or claims compliance. For instance, the International Finance Corporation's guide on eco-lodges does not claim to comply with the $\mathrm{CBD},{ }^{89}$ but the VCA-GDI's intention is that an area certified by it could declare its compliance with the CBD. The VCA-GDI lacks an (explicit) mandate for its conduct as a validating authority, yet it does not explicitly acknowledge that.

Second, the VCA-GDI justifies its existence by reference to the objectives of multilateral environmental treaties and to the international strategic orientations. The VCA-GDI explains that it contributes to the objectives of the CBD, but also those of the UN Convention to Combat Desertification and UN Framework Convention on Climate Change. ${ }^{90}$ Furthermore, it asserts that it implements six of twenty targets of the most recent Strategic Plan for Biodiversity 2011-2020, ${ }^{91}$ which were adopted by a COP decision. ${ }^{92}$ These tactics are interesting because legally speaking the listed

\footnotetext{
${ }^{84}$ National laws concerning protected areas establish standards. A particular standard for land management is given also by the EU's Directives 2009/147/EC (Birds Directive) and 92/43/EEC (Habitats Directive).

85 Affolder, op. cit. 83; see also the sector-specific standards for sustainable use that the GDI has identified at $<$ http://toolkit.earthmind.net/use/>

${ }^{86}$ N. Affolder, 'Cachet Not Cash: Another Sort of World Bank Group Borrowing' (2006) 14 Michigan State Law J. of International Law 141

87 See, e.g., CEMEX Biodiversity Action Plan (BAP) standard; CEMEX, Land Management and Biodiversity, <http://www.cemex.com/SustainableDevelopment/LandManagement.aspx>

${ }^{88}$ See, e.g., Important Bird Areas established by the NGO Birdlife International; BirdLife, Sites - Important Bird Areas, $<$ http://www.birdlife.org/datazone/site>; N. Dudley, Guidelines for applying protected area management categories (2008). Note that the IUCN is not a straightforward NGO, but a special kind of hybrid organisation, with both governments and NGOs as members.

89 International Finance Corporation, Ecolodges: Exploring Opportunities for Sustainable Business (2004), <http://toolkit.earthmind.net/files/IFC-Ecolodges-Exploring-Opportunities-for-Sustainable-Business.pdf>

${ }^{90} \mathrm{VCA}, \mathrm{n}$ above $81, \mathrm{p} 3-4$

${ }^{91}$ Ibid., at 4.

${ }^{92}$ UNEP/CBD/COP/10/2 (Strategic Plan for Biodiversity 2011-2020)
} 
international treaties continue to bind only States Parties and are also specifically addressed to them. Similarly, the COP decisions are normally adopted by and appeal to States Parties. ${ }^{93}$ By aligning with the latter, the VCA-GDI is likely to be counting on the credibility that is vested into COP decisions as sources of norms, since they are normally adopted by consensus of all States Parties. ${ }^{94}$ The VCA-GDI has relied heavily on its own claims of compliance with international objectives in order to bolster its own legitimacy. Declarations of compliance are intended to generate the same impression as the actual endorsement by the international institutions - observance of the international objectives. But contrary to the State consensus needed for the COP's endorsement of the initiative, the VCA-GDI is capable of retaining a full control of its own claims.

Thirdly, the VCA-GDI is keen on showcasing its close institutional links with the CBD treaty processes and organs. Using the Convention's logo on the VCA-GDI's promotional material ${ }^{95}$ and showing the affiliation of the previous Steering Committee members with the $\mathrm{CBD}^{96}$ may be seen only as symbolic acts. Nevertheless, they may generate an impression that the scheme is approved by the CBD. Other activities for securing recognition involve the VCA-GDI's presence at the CBD COPs and meetings leading to them ${ }^{97}$ and its releasing of statements specifically to influence the outcome

\footnotetext{
${ }^{93}$ A notable exemption is the decision UNEP/CBD/COP/8/17, devoted exclusively to private sector's engagement. Apart from addressing States, the decision also appeals directly to the private sector.

${ }^{94}$ CBD COP Rules of Procedure, Rule 40, para 1. Note however that the entire paragraph is bracketed "due to the lack of consensus among the Parties concerning the majority required for decision-making on matters of substance"; UNEP/CBD/COP/10/27 (Report of the Tenth Meeting of the Conference of the Parties to the Convention on Biological Diversity); Item 1.6., para 65.

${ }^{95}$ GDI, $\mathrm{n}$ above 59

${ }^{96}$ See GDM, About us, <http://earthmind.org/gdi/aboutus/>, where a previous member of a Steering Committee represented the CBD

${ }^{97}$ For a list of presence of the GDI initiative up to 2010, see GDM, Events, <http://gdm.earthmind.net/events/>.
} 
of the treaty process, ${ }^{98}$ including circulating of information reports to the states parties as part of the conference agenda. ${ }^{99}$

The VCA-GDI's careful creation of its image as being about "implementing an international plan" rather than "engaging the private sector" was reinforced after the GDM failed to secure endorsement of the CBD COP. The reframing is best understood by noting that the descriptions of the strategic sections of the presentational material changed from "innovative financial mechanism for biodiversity and development that would engage the private sector" 100 to "an international measure for biodiversityresponsible area management." 101 While the support for the CDB was never questioned, this is a meaningful stylistic shift that reflects a prioritization of values and approaches. It is likely to be a response to the resistance by some states to the engagement of the private sector and their stated preference for the international process over nontraditional initiatives.

Overall, the VCA-GDI's conduct can be interpreted as inconsistent: the mechanism justifies its existence by declaring the (State-led) treaty arrangements as ineffective but it simultaneously seeks (nearly universal) State endorsement. In constructing its legitimacy, the VCA-GDI combines the democratic and effectiveness principles that are expected from non-state authorities, as well as the consensus-based, treatygrounded "rules of the game" of State actors. If anything, such a mixed strategy reaffirms the useless demarcation between state and non-state law. ${ }^{102}$ It should however

\footnotetext{
${ }^{98}$ GDI, GDI4 Outcome Statement for the CBD Process, <http://gdi.earthmind.net/files/gdi4-outcome-statement-cbd-process.pdf>

${ }^{99} \mathrm{UNEP} / \mathrm{CBD} / \mathrm{COP} / 10 / \mathrm{INF} / 28$ (GDM 2010 Initiative report).

${ }^{100} \mathrm{GDM}, \mathrm{n}$ above 30 , at 4 .

${ }^{101}$ Earthmind, above n 44, p 3

${ }^{102}$ N. Affolder, 'The private life of environmental treaties' (2009) 103 American Journal of International Law 510
} 
be understood as a pragmatic plan, which addresses various relevant audiences (governmental and non-governmental). ${ }^{103}$

\section{CONCLUSION}

This article has made use of the legal transplant approach in the study of the GDM and its successors. The GDM was examined not so much to debate it as a promising governance mechanism for the biodiversity regime but to enrich the scholarship on transnational law.

At the most fundamental level, a careful empirical analysis of the GDM contributes to the nuanced understanding of the design and functioning of contemporary transnational (environmental) governance processes that recognize the contribution of non-state actors in law-making and acknowledge rules other than those enshrined in international treaties. ${ }^{104}$ The diversity and unpredictable dynamics of the transnational space shines out of the case of the GDM.

At the same time, the present case makes a theoretical proposition of introducing the scholarship on legal transplants - a means of ensuring "sensitivity to the peculiarities" in legal jurisdictions ${ }^{105}$ - to the transnational plane. Specifically, it points to moves of legal ideas between two transnational regimes as a distinct, so far unexplored, transplantation route. What came out of the transplantation (the GDI-VCA) is

\footnotetext{
${ }^{103}$ See M. Beisheim and K. Dingwerth, Procedural Legitimacy and Private Transnational Governance. Are the Good Ones Doing Better? (2008) SFB-Governance Working Paper Series, No. 14, p. 5-6.

${ }^{104}$ In the environmental context, see D. Bodansky, The Art and Craft of International Environmental Law (Cambridge, MA: Harvard University Press, 2010); K. O’Neill, The Environment and International Relations (Cambridge: Cambridge University Press 2011); contributions to the journal Transnational Environmental Law.

${ }^{105}$ L. Zender, 'In Pursuit of the Vernacular: Comparing Law and Order Discourse in Briatin and Germany' (1995) 4 Social and Legal Studies 517, p 519; see also P. Legrand, 'The Same and the Different', in P. Legrand \& R. Munday (eds) Comparative Legal Studies (Cambridge: Cambridge University Press, 2011) 240, at 281.
} 
ultimately very different, in both institutional and operational aspects, from a direct replication of the original idea (the CDM). This particular transplantation reiterates the scepticism in the transferability of law, but does this at the transnational plane, depicting it as composed of segments of legal cultures, rather than any uniform features.

The law-as-transplant approach further compels us to provide explanation for the difference, both institutional and operational, between the intention and the result. In the story just presented, the notion of legitimacy plays a key role: it explains why a transplant has been attempted (to import legitimacy), why that attempt was unsuccessful (because there are different legitimacy communities) and why the redesign after the failed transplant took the shape it did (to simultaneously address various legitimacy communities).

A particularly intriguing part of the transplantation story is to note that metaphors derived from "successful" legal ideas continually retain a certain attraction as legal fixes, despite their capability of transcending the intentions of their promoters in unanticipated directions. As the legal transplanting from the GDM to the VCA-GDI highlights, metaphors create consciousness of the stakeholders, but they are used on the presumption that the meaning of the metaphor is shared, when it can also be highly divisive, and on the presumption that one thing (a legal model) can be equated with another, when actual similarities can be weak.

The failure of metaphors to converse a consensual meaning is a reflection of the diversity of the transnational space. Here, instead of encountering one "transnational legal culture", legal proposals hit against several ideologies and worldviews within the same regime. These constitute distinct audiences to appeal to in constructing legitimacy. Blueprints about how legal mechanisms can ensure their acceptance in the 
transnational context are futile, but the inspected transplanting experience offers some lessons that are prior to those guidelines. First, the construction of legitimacy is a separate issue from importing a legal idea itself. Second, legitimacy of the mechanism cannot be "inherited" from a predecessor (or a prototype) and easily replicated. And yet, without legitimacy, the mechanism cannot function. Third, the presumed distinction between state and non-state actors is a scholarly construct that is neither an accurate descriptor of today's actors nor helpful in anticipating their tactics aiming at acceptance or recognition by those they seek to govern. In discovering effective legitimating tactics deployed by transnational initiatives, sorting the subjects (or initiatives seeking recognition) into preconceived types of actors will not yield meaningful conclusions. Instead, we should be paying attention to the objects of legitimating efforts (or target legitimacy communities) and the contexts of their relations to other legitimacy communities. 